\title{
Aureosurfactin and 3-deoxyaureosurfactin, novel biosurfactants produced by Aureobasidium pullulans L3-GPY
}

\author{
Jong-Shik Kim ${ }^{1}$, In-Kyoung Lee ${ }^{2}$, Dae-Won Kim ${ }^{2}$ and Bong-Sik Yun ${ }^{2}$ \\ The Journal of Antibiotics (2016) 69, 759-761; doi:10.1038/ja.2015.141; published online 13 January 2016
}

Surfactants are characterized by physical properties such as dispersibility, emulsifiability, permeability, wettability and bubble-forming capability. These molecules have both hydrophilic and hydrophobic moieties in their structures that can accumulate at interfaces, reduce surface and interfacial tensions, and form aggregate structures such as micelles, which consist of external hydrophilic moieties and internal hydrophobic moieties. ${ }^{1-6}$ Chemical surfactants are currently used in various industrial fields including electronics, construction, mechanics, printing, papers and fibers.

Biosurfactant is a comprehensive term including all kinds of organism-derived surfactant materials, although it generally refers to a surfactant material synthesized by a microorganism. Biosurfactants produced in vivo or in vitro by microorganisms, such as yeasts, fungi or bacteria, are more eco-friendly than chemical surfactants in that they are non-toxic and biodegradable. ${ }^{1-6}$ Although biosurfactants have complex chemical structures that are difficult to synthesize according to the conventional methods, these compounds are useful and can be used for specific purposes. Furthermore, biosurfactants have nearly the same effects as conventional chemical surfactants with regards to physical and chemical properties including surface tension reduction and temperature/pH stabilization. ${ }^{3-6}$ Thus, like chemical surfactants, biosurfactants have wide applications in various industrial fields such as medicine, foods, cosmetics, cleaning materials, secondary oil recovery and the bioremediation of oil-contaminated land and seawater. ${ }^{4,5}$

Aureobasidium pullulans is a ubiquitous yeast reportedly found in various locations. Research on A. pullulans has described (poly) malic acid, ${ }^{7}$ lipase ${ }^{8}$ laccase, ${ }^{9}$ mannitol oils, ${ }^{10}$ biocontrol, ${ }^{11}$ lipid composition $^{12}$ and siderophores. ${ }^{13}$ A. pullulans strains also reportedly produce biosurfactants of heavy oils. ${ }^{14}$ In a previous study, we reported the isolation of a novel biosurfactant, glycerol-liamocin, from the culture broth of Aureobasidium pullulans L3-GPY. ${ }^{15}$ Further study on the fermentation of this strain using a high glycerol content, led to the isolation of two new biosurfactants, aureosurfactin and 3-deoxyaureosurfactin (Figure 1), from its culture supernatant. In this study, we describe the isolation and structure determination of these compounds, as well as their biosurfactant abilities.

For seed culture of A. pullulans L3-GPY, an inoculant was prepared by cultivating the producing organism for $48 \mathrm{~h}$ at $25^{\circ} \mathrm{C}$ in a $50-1$ jar fermentor (KoBiotech, Icheon, Korea) with 251 of the GPY broth medium containing $0.5 \%$ peptone, $0.5 \%$ yeast extract and $4 \%$ glycerol as a carbon source. The fermentation was aerobically carried out in a $300-1$ jar fermentor (KoBiotech) for $136 \mathrm{~h}$ at $25^{\circ} \mathrm{C}$ with $200 \mathrm{l}$ of the medium consisting of $0.5 \%$ peptone, $0.5 \%$ yeast extract and $4 \%$ glycerol as a carbon source.

The harvested culture broth was centrifuged twice at 15000 r.p.m. to obtain the supernatant. The culture supernatant was freeze-dried, dissolved in water and then filtered with gauze to eliminate insoluble debris. The filtrate was partitioned twice between ethyl acetate and water. The ethyl acetate-soluble portion was concentrated under reduced pressure and subjected to a flash silica gel column chromatography eluted with chloroform: methanol $\left(\mathrm{CHCl}_{3}: \mathrm{MeOH}=50: 1 \rightarrow 2\right.$ : $1, \mathrm{v} / \mathrm{v}$, stepwise $)$. An active fraction $\left(\mathrm{CHCl}_{3}: \mathrm{MeOH}=50: 1\right.$ fraction) showing strong desired activities was concentrated and subjected to flash reversed-phase octadecylsilane (ODS) column chromatography eluted with $60,70,80$ and $90 \%$ aqueous methanol to provide two active fractions, Fr. 1 (80\% aqueous methanol eluate) and Fr. 2 (90\% aqueous methanol eluate). First, fraction 1 was concentrated under reduced pressure and subjected to silica gel column chromatography eluted with chloroform: methanol (100: $1 \rightarrow 5: 1, \mathrm{v} / \mathrm{v}$, stepwise). Active fractions were then combined and concentrated under reduced pressure. The concentrate was chromatographed on a Sephadex LH-20 (Amersham Biosciences, Uppsala, Sweden) column eluted with $70 \%$ aqueous methanol, followed by a Sep-pak $\mathrm{C}_{18}$ cartridge (Waters, Milford, MA, USA) eluted with 50, 60 and 70\% aqueous methanol stepwise. Finally, aureosurfactin was purified by preparative silica gel

\footnotetext{
${ }^{1}$ Gyeongbuk Institute for Marine Bio-industry, Uljin, Korea and ${ }^{2}$ Division of Biotechnology and Advanced Institute of Environmental and Bioscience, College of Environmental and Bioresource Sciences, Chonbuk National University, Iksan-si, Korea Correspondence: Dr J-S Kim, Gyeongbuk Institute for Marine Bio-industry, Haeyanggwahak-gil 22, Uljin, Gyeongbuk 767-813, Korea.

E-mail: jskim@gimb.or.kr

or Professor B-S Yun, Division of Biotechnology and Advanced Institute of Environment and Bioscience, College of Environmental and Bioresource Sciences, Chonbuk National University, Gobong-ro 79, Iksan 570-752, Korea.

E-mail: bsyun@jbnu.ac.kr

Received 6 October 2015; revised 11 November 2015; accepted 7 December 2015; published online 13 January 2016
} 


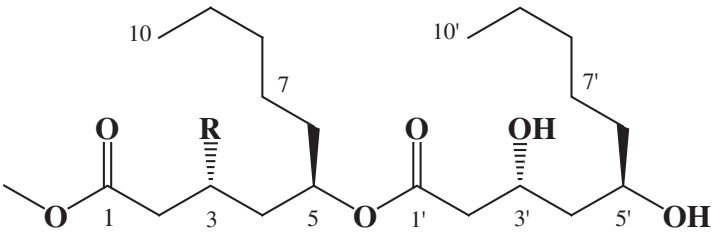

Aureosurfactin: $\mathrm{R}=\mathrm{OH}$

3-Deoxyaureosurfactin: $\mathrm{R}=\mathrm{H}$

Figure 1 Structures of aureosurfactin and 3-deoxyaureosurfactin.

TLC developed with hexane: ethyl acetate (1:1, v/v). 3Deoxyaureosurfactin was purified from active fraction 2 , which was concentrated under reduced pressure and chromatographed on a column of silica gel eluted with chloroform: methanol $(30: 1 \rightarrow 5: 1, \mathrm{v} / \mathrm{v}$, stepwise). Active fractions were combined, concentrated and subjected to a Sephadex LH-20 column chromatography eluted with methanol, followed by silica gel column chromatography eluted with hexane: ethyl acetate (20: $1 \rightarrow 1: 1, \mathrm{v} / \mathrm{v}$, stepwise). An active eluate was concentrated and chromatographed on a ODS Sepak cartridge eluted with 50, 60 and $70 \%$ aqueous methanol, followed by preparative silica gel TLC developed with chloroform: methanol $(15: 1, \mathrm{v} / \mathrm{v})$ to afford 3deoxyaureosurfactin.

Aureosurfactin was obtained as a colorless oil. The MW of the compound was determined to be 404 by the ESI-mass measurement, which provided a quasi-molecular ion peak at $m / z 427[\mathrm{M}+\mathrm{Na}]^{+}$in positive mode, and the molecular formula was established as $\mathrm{C}_{21} \mathrm{H}_{40} \mathrm{O}_{7}$ by high-resolution FAB-mass measurement $(\mathrm{m} / \mathrm{z} 427.2671$ $[\mathrm{M}+\mathrm{Na}]^{+}, \Delta-0.1$ m.m.u.) in combination with ${ }^{1} \mathrm{H}$ and ${ }^{13} \mathrm{C}$ NMR data. This molecular formula requires two degrees of unsaturation. The ${ }^{1} \mathrm{H}$ NMR spectrum measured in $\mathrm{CDCl}_{3}$ showed signals due to four oxygenated methines at $\delta 5.05,4.23,4.08$ and 3.81, one methoxy at $\delta 3.66,12$ methylenes at $\delta 2.47 / 2.41,2.42,1.80 / 1.62,1.53(\times 2)$, $1.43 / 1.37,1.37 / 1.26,1.26 / 1.24$ and $1.25(\times 4)$, and two methyls at $\delta$ 0.84 (Table 1). In the ${ }^{13} \mathrm{C}$ NMR spectrum, 21 carbons were evident and assigned as two ester carbonyl carbons at $\delta 172.8$ and 172.1, four oxygenated methine carbons at $\delta 72.7,72.1,69.5$ and 66.2, one methoxyl carbon at $\delta 51.8,12$ methylene carbons at $\delta 42.7,42.3,41.3$, $40.7,37.7,34.4,31.7,31.5,25.0,24.7,22.5$ and 22.4, and two methyl carbons at $\delta 14.0$ and 13.9. All proton-bearing carbons were established by the HMQC spectrum and four partial structures, $\mathrm{CH}_{2}-\mathrm{CH}(-\mathrm{O})-\mathrm{CH}_{2}-\mathrm{CH}(-\mathrm{O})-\mathrm{CH}_{2}-,-\mathrm{CH}_{2}-\mathrm{CH}(-\mathrm{O})-\mathrm{CH}_{2}-\mathrm{CH}(-\mathrm{O})-$ $\mathrm{CH}_{2}-, \mathrm{CH}_{3}-\mathrm{CH}_{2}-$ and $\mathrm{CH}_{3}-\mathrm{CH}_{2-}$, were determined by the ${ }^{1} \mathrm{H}-{ }^{1} \mathrm{H}$ COSY spectrum. The chemical structure was determined by the $\mathrm{HMBC}$ spectrum, which showed long-range correlations from the methylene protons at $\delta 2.47 / 2.41(\mathrm{C}-2)$ and the methoxy protons at $\delta$ 3.66 to the carbonyl carbon at $\delta 172.8(\mathrm{C}-1)$, revealing that the methoxy group was attached to $\mathrm{C}-1$. The methyl protons at $\delta 0.84$ and the methylene protons at $\delta 1.53$ exhibited long-range correlations to the methylene carbons at $\delta 31.5$ (C-8), suggesting the 3,5-dihydroxydecanoyl methyl ester. Another 3,5-dihydroxydecanoyl moiety was established due to long-range correlations from the methylene protons at $\delta 2.42\left(\mathrm{C}-2^{\prime}\right)$ to the carbonyl carbon at $\delta 172.1\left(\mathrm{C}-1^{\prime}\right)$ and from the methyl protons at $\delta 0.84$ and the methylene protons at $\delta 1.43 / 1.37$ to the methylene carbon at $\delta 31.7\left(\mathrm{C}-8^{\prime}\right)$. Two 3,5-dihydroxydecanoyl moieties were connected by long-range correlation from the methine proton at $\delta 5.05$ (C-5) to the carbonyl carbon at $\delta 172.1\left(\mathrm{C}-1^{\prime}\right)$. Thus, the structure of aureosurfactin was determined as shown in Figure 2.
Table $1{ }^{1} \mathrm{H}$ and ${ }^{13} \mathrm{C}$ NMR spectral data of aureosurfactin and 3-deoxyaureosurfactin in $\mathrm{CDCl}_{3}{ }^{\mathrm{a}}$

\begin{tabular}{|c|c|c|c|c|}
\hline \multirow[b]{2}{*}{ No. } & \multicolumn{2}{|c|}{ Aureosurfactin } & \multicolumn{2}{|c|}{ 3-Deoxyaureosurfactin } \\
\hline & $\delta_{C}$ & $\delta_{H}$ & $\delta_{C}$ & $\delta_{H}$ \\
\hline 1 & 172.8 & & 173.8 & \\
\hline 2 & 41.3 & $2.47(\mathrm{~m}), 2.41(\mathrm{~m})^{\mathrm{b}}$ & 33.6 & $2.32(\mathrm{~m})$ \\
\hline 3 & 66.2 & $4.08(\mathrm{~m})$ & 20.5 & $1.64(\mathrm{~m}), 1.59(\mathrm{~m})$ \\
\hline 4 & 40.7 & $1.80(\mathrm{~m}), 1.62(\mathrm{~m})$ & 33.3 & $1.53(\mathrm{~m})$ \\
\hline 5 & 72.7 & $5.05(\mathrm{~m})$ & 74.3 & $4.93(\mathrm{~m})$ \\
\hline 6 & 34.4 & $1.53(\mathrm{~m})$ & 33.9 & $1.45(\mathrm{~m})$ \\
\hline 7 & 24.7 & $1.37(\mathrm{~m}), 1.26(\mathrm{~m})$ & 25.0 & $1.29(\mathrm{~m})$ \\
\hline 8 & 31.5 & $1.25(\mathrm{~m})$ & 31.6 & $1.29(\mathrm{~m})$ \\
\hline 9 & 22.4 & $1.25(\mathrm{~m})$ & 22.5 & $1.30(\mathrm{~m})$ \\
\hline 10 & 13.9 & 0.84 & 14.0 & 0.88 \\
\hline $1^{\prime}$ & 172.1 & & 172.4 & \\
\hline $2^{\prime}$ & 42.7 & $2.42(\mathrm{~m})$ & 41.9 & $2.48(\mathrm{~m})$ \\
\hline $3^{\prime}$ & 69.5 & $4.23(\mathrm{~m})$ & 69.2 & $4.28(\mathrm{~m})$ \\
\hline $4^{\prime}$ & 42.3 & $1.53(\mathrm{~m})$ & 42.3 & $1.57(\mathrm{~m})$ \\
\hline $5^{\prime}$ & 72.1 & $3.81(\mathrm{~m})$ & 72.2 & $3.88(\mathrm{~m})$ \\
\hline $6^{\prime}$ & 37.7 & $1.43(\mathrm{~m}), 1.37(\mathrm{~m})$ & 37.8 & $1.50(\mathrm{~m}), 1.42(\mathrm{~m})$ \\
\hline $7^{\prime}$ & 25.0 & $1.26(\mathrm{~m}), 1.24(\mathrm{~m})$ & 25.1 & $1.29(\mathrm{~m})$ \\
\hline $8^{\prime}$ & 31.7 & $1.25(\mathrm{~m})$ & 31.8 & $1.29(\mathrm{~m})$ \\
\hline $9^{\prime}$ & 22.5 & $1.25(\mathrm{~m})$ & 22.6 & $1.30(\mathrm{~m})$ \\
\hline $10^{\prime}$ & 14.0 & 0.84 & 14.0 & 0.89 \\
\hline $\mathrm{OMe}$ & 51.8 & $3.66(\mathrm{~s})$ & 51.6 & $3.67(\mathrm{~s})$ \\
\hline
\end{tabular}

aNMR data were recorded at $600 \mathrm{MHz}$ for protons and $150 \mathrm{MHz}$ for carbons. bProton resonance multiplicity in parentheses.



Figure 2 HMBC correlations of aureosurfactin.

3-Deoxyaureosurfactin was obtained as a colorless oil. Its MW was determined to be 388 by ESI-mass measurement, which provided a quasi-molecular ion peak at $\mathrm{m} / z 411[\mathrm{M}+\mathrm{Na}]^{+}$in positive mode. The molecular formula was established as $\mathrm{C}_{21} \mathrm{H}_{40} \mathrm{O}_{6}$ by high-resolution FAB-mass measurement $\left(\mathrm{m} / \mathrm{z} 411.2736[\mathrm{M}+\mathrm{Na}]^{+}, \Delta+1.4 \mathrm{~m}\right.$.m.u. $)$ in combination with ${ }^{1} \mathrm{H}$ and ${ }^{13} \mathrm{C}$ NMR data. The ${ }^{1} \mathrm{H}$ NMR spectrum in $\mathrm{CDCl}_{3}$ showed signals due to three oxygenated methines at $\delta 4.93$, 4.28 and 3.88 , one methoxyl at $\delta 3.69,13$ methylenes at $\delta 2.48,2.32$, $1.64 / 1.59,1.57,1.53,1.50 / 1.42,1.45,1.30(\times 2)$ and $1.29(\times 4)$, and two methyls at $\delta 0.89$ and 0.88 (Table 1 ). In the ${ }^{13} \mathrm{C}$ NMR spectrum, 21 carbons, including two ester carbonyl carbons at $\delta 173.8$ and 172.4, three oxygenated methine carbons at $\delta 74.3,72.2$ and 69.2 , one methoxy carbon at $\delta 51.6,13$ methylene carbons at $\delta 42.3,41.9,37.8$, $33.6,33.9,33.3,31.8,31.6,25.1,25.0,22.6,22.5$ and 20.5, and two methyl carbons at $\delta 14.0$, were evident. ${ }^{1} \mathrm{H}$ and ${ }^{13} \mathrm{C}$ NMR spectra were very similar to those of aureosurfactin, except that an oxygenated methine in aureosurfactin was replaced by a methylene in 




1
1.

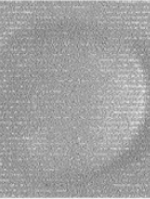

2

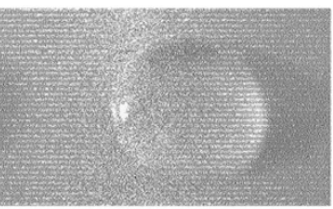

3
Figure 3 Surface tension abilities of aureosurfactin and 3-deoxyaureosurfactin in aqueous solution dropped on hydrophobic film. 1 water; 2 aureosurfactin; 3 3-deoxyaureosurfactin.

3-deoxyaureosurfactin. All proton-bearing carbons were established by the HMQC spectrum and the ${ }^{1} \mathrm{H}-{ }^{1} \mathrm{H}$ COSY spectrum revealed four partial structures, $-\mathrm{CH}_{2}-\mathrm{CH}_{2}-\mathrm{CH}_{2}-\mathrm{CH}(-\mathrm{O})-\mathrm{CH}_{2}-,-\mathrm{CH}_{2}-\mathrm{CH}(-\mathrm{O})-$ $\mathrm{CH}_{2}-\mathrm{CH}(-\mathrm{O})-\mathrm{CH}_{2}-, \mathrm{CH}_{3}-\mathrm{CH}_{2}-$ and $\mathrm{CH}_{3}-\mathrm{CH}_{2}-$, revealing that $\mathrm{C}-3$ was reduced. The HMBC spectrum established two partial units, 5-hydroxydecanoate methyl ester and 3,5-dihydroxydecanoate. Finally, the structure of 3-deoxyaureosurfactin was determined by the longrange correlation from the methine proton at $\delta 4.93(\mathrm{C}-5)$ to the carbonyl carbon at $\delta 172.4\left(\mathrm{C}-1^{\prime}\right)$. The relative stereochemistries of these compounds were deduced from related compounds, namely exophilin and halymecins. ${ }^{16,17}$ The ${ }^{13} \mathrm{C}$ NMR peaks were in good agreement with these known compounds and 3R,5R-dihydroxydecanoic acid. Thus, the relative stereochemistry of these compounds was deduced, as shown in Figure 2. However, absolute stereochemistry remains to be investigated.

Surfactant activity was determined by dissolving a compound in water, loading $20 \mu \mathrm{l}$ of the resulting solution on Parafilm, and measuring the degree of spreading (Figure 3). ${ }^{18}$ The degree of spreading of a compound was represented by diameter. An equal amount of distilled water was used as a control. Surface tension variation of the purified surfactant solutions was determined using a Du Noüy ring tensiometer (Sigma Model 700 instrument, KSV Instruments Ltd, Helsinki, Finland) that is submersed in a liquid. As the ring is pulled out of the liquid, the force required is precisely measured to determine the surface tension of the liquid. ${ }^{19}$ Aureosurfactin and 3-deoxyaureosurfactin showed surface tension activities of 29.5 and 36.4 dyne $\mathrm{cm}^{-1}$, respectively, at $1.0 \mathrm{mgl}^{-1}$. These activities were comparable to known biosurfactants, rhamnolipid, surfactin and sophorolipid. ${ }^{1}$ Due to the active components of A. pullulans L3-GPY culture broth, specifically aureosurfactin and 3-deoxyaureosurfactin, the findings presented herein suggest the usefulness of this material as a biosurfactant.

\section{CONFLICT OF INTEREST}

The authors declare no conflict of interest.

\section{ACKNOWLEDGEMENTS}

This work was supported by the research program of Gyeongsangbuk-Do and the National Research Foundation of Korea (NRF), via a grant from the Korean government (MSIP) (no. NRF-2014R1A2A1A11052888).

1 Desai, J. D. \& Banat, I. M. Microbial production of surfactants and their commercia potential. Microbiol. Mol. Biol. Rev. 61, 47-64 (1997).

2 Kitamoto, D., Isoda, H. \& Nakahara, T. Functions and potential applications of glycolipid biosurfactants-from energy-saving materials to gene delivery carriers. J. Biosci. Bioeng. 94, 187-201 (2002).

3 Ron, E. Z. \& Rosenberg, E. Natural roles of biosurfactants. Environ. Microbiol. 3, 229-236 (2001).

4 Singh, A., Van Hamme, J. D. \& Ward, O. P. Surfactants in microbiology and biotechnology: Part 2. Application aspects. Biotechnol. Adv. 25, 99-121 (2007).

5 Van Hamme, J. D., Singh, A. \& Ward, O. P. Physiological aspects: Part 1 in a series of papers devoted to surfactants in microbiology and biotechnology. Biotechnol. Adv. 24, 604-620 (2006).

6 Rodrigues, L., Banat, I. M., Teixeira, J. \& Oliveira, R. Biosurfactants: potential applications in medicine. J. Antimicrob. Chemother. 57, 609-618 (2006).

7 Leathers, T. D. \& Manitchotpisit, P. Production of poly( $\beta$-L-malic acid)(PMA) from agricultural biomass substrates by Aureobasidium pullulans. Biotechnol. Lett. 35, 83-89 (2013).

8 Leathers, T. D., Rich, J. O., Anderson, A. M. \& Manitchotpisit, P. Lipase production by diverse phylogenetic clades of Aureobasidium pullulans. Biotechnol. Lett. 35, 1701-1706 (2013).

9 Rich, J. O., Manitchotpisit, P., Peterson, S. W. \& Leathers, T. D. Laccase production by diverse phylogenetic clades of Aureobasidium pullulans. Rangsit J. Arts Sci. 1, 41-47 (2011)

10 Price, N. P. J., Manitchotpisit, P., Vermillion, K. E., Bowman, M. J. \& Leathers, T. D. Structural characterization of novel extracellular liamocins (mannitol oils) produced by Aureobasidium pullulans strain NRRL 50380. Carbohydr. Res. 370, 24-32 (2013).

11 Mari, M., Martini, C., Spadoni, A., Rouissi, W. \& Bertolini, P. Biocontrol of apple postharvest decay by Aureobasidium pullulans. Postharvest Biol. Technol. 73, 56-62 (2012).

12 Čertík, M., Breierová, E. \& Juršíková, P. Effect of cadmium on lipid composition of Aureobasidium pullulans grown with added extracellular polysaccharides. Int. Biodeter. Biodegr 55, 195-202 (2005).

13 Ma, Z. C., Chi, Z., Geng, Q., Zhang, F. \& Chi, Z. M. Disruption of the pullulan synthetase gene in siderophore-producing Aureobasidium pullulans enhances siderophore production and simplifies siderophore extraction. Process Biochem. 47, 1807-1812 (2012).

14 Manitchotpisit, P., Price, N. P., Vermillion, K. E., Leathers, T. D. \& Punnapayak, H. Heavy oils produced by Aureobasidium pullulans. Biotechnol. Lett. 33, 1151-1157 (2011)

15 Kim, J. S., Lee, I. K. \& Yun, B. S. A novel biosurfactant produced by Aureobasidium pullulans L3-GPY from a tiger lily wild flower, Lilium lancifolium Thunb. PLOS ONE 10, e0122917 (2015).

16 Doshida, J., Hasegawa, H., Onuki, H. \& Shimidzu, N. Exophilin A, a new antibiotic from a marine microorganism Exophiala pisciphila. J. Antibiot. 49, 1105-1109 (1996).

$17 \mathrm{Chen}, \mathrm{C}$. et al. Halymecins, new antimicroalgal substances produced by fungi isolated from marine algae. J. Antibiot. 49, 998-1005 (1996)

18 Jain, D. K., Collins-Thompson, D. L., Lee, H. \& Trevors, J. T. A drop-collapsing test for screening surfactant-producing microorganisms. J. Microbiol. Methods 13, 271-279 (1991).

19 Mclnerney, M. J., Javaheri, M. \& Nagle, D. P. Jr. Properties of the biosurfactant produced by Bacillus licheniformis strain JF-2. J. Ind. Microbiol. 5, 95-101 (1990). 